\title{
The lactate dehydrogenase-elevating virus capsid protein is a nuclear-cytoplasmic protein
}

\author{
Hakimeh Mohammadi · Shayan Sharif • \\ Raymond R. Rowland · Dongwan Yoo
}

Received: 9 March 2009/Accepted: 25 May 2009/Published online: 11 June 2009

(C) Springer-Verlag 2009

\begin{abstract}
Arteriviruses replicate in the cytoplasm and do not require the nucleus function for virus multiplication in vitro. However, nucleocapsid $(\mathrm{N})$ protein of two arteriviruses, porcine reproductive respiratory syndrome virus and equine arteritis virus, has been observed to localize in the nucleus and nucleolus of virus-infected and N-gene-transfected cells in addition to their normal cytoplasmic distribution. In the present study, the $\mathrm{N}$ protein of lactate dehydrogenase-elevating virus (LDV) of mice was examined for nuclear localization. The subcellular localization of LDV-N was determined by tagging $\mathrm{N}$ with enhanced green fluorescence protein (EGFP) at the $\mathrm{N}$ - and $\mathrm{C}$-terminus. Both N-EGFP and EGFP-N fusion proteins localized to the nucleus and nucleolus of gene-transfected cells. Labeled $\mathrm{N}$ also accumulated in the perinuclear region, the site of virus replication. The LDV-N sequence contains a putative 'pat4'-type nuclear localization signal (NLS) consisting of 38-KKKK. To determine its functional significance, a series of deletion constructs of $\mathrm{N}$ were generated and individually expressed in cells. The results showed that the 'pat4' NLS was essential for nuclear translocation. In addition, the LDV-N interacted with the importin $-\alpha$ and $-\beta$ proteins, suggesting that the LDV-N
\end{abstract}

H. Mohammadi · S. Sharif

Department of Pathobiology, University of Guelph,

Guelph, ON N1G 2W1, Canada

R. R. Rowland

Department of Diagnostic Medicine and Pathobiology,

Kansas State University, Manhattan, KS 66506, USA

D. Yoo $(\bowtie)$

Department of Pathobiology, University of Illinois

at Urbana-Champaign, 2001 South Lincoln Avenue,

Urbana, IL 61802, USA

e-mail: dyoo@illinois.edu nuclear localization may occur via the importin-mediated nuclear transport pathway. These results provide further evidence for the nuclear localization of $\mathrm{N}$ as a common feature within the arteriviruses.

\section{Introduction}

Lactate dehydrogenase-elevating virus (LDV) is a murine virus causing lifelong persistent viremia in mice with no apparent clinical signs except an increased level of the plasma enzyme lactate dehydrogenase [4, 22, 24, 29]. LDV shows limited in vitro replication, which is restricted to specific murine primary macrophages and presents a low level of virus production in culture [2, 3, 20,33]. LDV is an RNA virus with a diameter of $62-80 \mathrm{~nm}$ that belongs to the family Arteriviridae, a family of viruses whose members contain a single-stranded positive-sense RNA genome and which includes three other member viruses: porcine reproductive and respiratory syndrome virus (PRRSV), equine arteritis virus (EAV), and simian hemorrhagic fever virus (SHFV) [31]. The family Arteriviridae is grouped in the order Nidovirales along with the family Coronaviridae. Arteriviruses infect macrophages in the host animal and are responsible for a number of important diseases such as abortion and respiratory disorders in pigs by PRRSV, persistent viremia in mice by LDV, abortion and arteritis in horses by EAV, and hemorrhagic fever in monkeys by SHFV $[15,18,32]$.

The LDV genome is $14.1 \mathrm{~kb}$ in length, dominated by two large open reading frames, ORF1a and ORF1ab, in the $5^{\prime}$ three-fourths of the genome, which code for two large polyproteins, PP1a and PP1ab. The polyproteins are predicted to be proteolytically cleaved into 12 cleavage products designated non-structural protein 1 (Nsp1) through 
Nsp12. Downstream from ORF1ab are ORF2 through ORF7, which encode at least seven structural proteins: GP2a, GP2b (E), GP3, GP4, GP5, matrix (M) and nucleocapsid $(\mathrm{N})$ proteins [32]. The nucleocapsid protein of LDV is 115 amino acids in length and is the most abundant protein within the virion.

Nidoviruses replicate exclusively in the cytoplasm. However, the $\mathrm{N}$ protein of PRRSV, EAV and the coronaviruses avian infectious bronchitis virus (IBV) and transmissible gastroenteritis virus (TGEV) localize to the nucleolus [25, 35, 40]. An interesting exception is the $\mathrm{N}$ protein of SARS-CoV. One study showed that SARS-CoV $\mathrm{N}$ protein is localized exclusively in the cytoplasm [28], while other studies have reported that the SARS-CoV $\mathrm{N}$ protein is present in the both the cytoplasm and the nucleus/nucleolus [43, 44]. These findings suggest that localization of $\mathrm{N}$ to the nucleolus may not be a general property for all nidovirus $\mathrm{N}$ proteins. Once in the nucleus, the PRRSV and IBV N proteins interact with fibrillarin and nucleolin and may be involved in the cell cycle regulation [5, 40, 42]. For nuclear proteins, trafficking between the cytoplasm and the nucleus occurs through the nuclear pore complexes (NPC). While small molecules enter the nucleus by diffusion through NPC, large molecules enter the nucleus by an energy-dependent pathway using a nuclear localization signal (NLS) [8]. The NLS on the cargo protein interacts with importin proteins in the cytoplasm, which are then shuttled across the NPC and into the nucleus. Three types of NLSs have been identified. A "pat4"-type NLS is a stretch of four basic amino acids such as 'KKKK'. A second type is "pat7", which is a string of amino acids starting with proline $(\mathrm{P})$ followed by any other two amino acids, followed by four amino acids of which at least three are basic residues. The third type is a bipartite form. The bipartite NLS has two areas of basic residues separated by 10-12 amino acids. The first group of basic residues includes two basic amino acids, and the second group contains five amino acids, consisting of at least three basic residues [16, 26]. In this report, we examined the $\mathrm{N}$ protein nuclear localization of LDV and identified a functional 'pat-4' signal sequence essential for $\mathrm{N}$ protein translocation into the nucleus.

\section{Materials and methods}

Cells, viruses, and bacterial strains

MARC-145 cells [13], a derivative of MA-104 cells, HeLa cells, and NIH-3T3 cells were used for this study. Cells were maintained in Dulbecco's modified Eagle's medium (DMEM) supplemented with 10\% heat-inactivated fetal bovine serum (FBS, Invitrogen, Carlsbad, CA) in a humidified incubator with $5 \% \mathrm{CO}_{2}$ at $37^{\circ} \mathrm{C}$. PRRSV strain PA8 [38] was grown in MARC-145 cells. E. coli strains DH5 $\alpha$ and XL-1 Blue (Stratagene, La Jolla, CA) were used for gene cloning and mutagenesis, and strain BL-21 (Stratagene) was used for protein expression.

\section{Plasmid constructions}

The LDV-N gene was amplified by PCR from a plasmid containing the LDV genomic fragment, and using the BamHI sequences at the ends of both primers, cloned into pEGFP-N1 and pEGFP-C1 (Clontech, Mountain View, CA) upstream and downstream, respectively, of the enhanced green fluorescence protein (EGFP) gene. LDV-N was also subcloned using BamHI into pCITE-2C (Novagen) for in vitro transcription and translation.

\section{Mutant construction for LDV-N}

Deletion constructs of LDV-N were made by PCR using the appropriate primer sets (Table 1) under the following
Table 1 List of the primers used for EGFP fusion constructions for LDV-N

\begin{tabular}{|c|c|c|}
\hline Construct & Primer pair & Sequence $^{\mathrm{a}}$ \\
\hline \multirow[t]{2}{*}{ LDV-N-EGFP } & N-EGFP-FWD & 5'-ATggatccATGTCTCAAAATAAGAAGAA-3' \\
\hline & N-EGFP-REV & 5'-ATggatccGAAGCAGAAGAATTAGCAGAAG-3' \\
\hline \multirow[t]{2}{*}{ EGFP-LDV-N } & EGFP-N-FWD & 5'-ATggatccATGTCTCAAAATAAGAAGAA-3' \\
\hline & EGFP-N-REV & 5'-ATggatccTTAAGCAGAAGAATTAGCAG-3' \\
\hline \multirow[t]{2}{*}{$\mathrm{LDV}-\mathrm{N}-\Delta \mathrm{C} 40$} & $\mathrm{~N}-\Delta \mathrm{C} 40-\mathrm{FWD}$ & 5'-ATggatccATGTCTCAAAATAAGAAGAA-3' \\
\hline & $\mathrm{N}-\triangle \mathrm{C} 40-\mathrm{REV}$ & 5'-ATggatccGACAGCTTGGGCTGCTTCTTCTT-3' \\
\hline \multirow[t]{2}{*}{ LDV-N- $\Delta \mathrm{C} 65$} & $\mathrm{~N}-\Delta \mathrm{C} 65-\mathrm{FWD}$ & 5'-ATggatccATGTCTCAAAATAAGAAGAA-3' \\
\hline & $\mathrm{N}-\triangle \mathrm{C} 65-\mathrm{REV}$ & 5'-ATggatccGACGCCATAGGGAAGTGCAGCTT-3' \\
\hline \multirow[t]{2}{*}{$\mathrm{LDV}-\mathrm{N}-\Delta \mathrm{C} 70$} & $\mathrm{~N}-\Delta \mathrm{C} 70-\mathrm{FWD}$ & 5'-ATggatccATGTCTCAAAATAAGAAGAA-3' \\
\hline & $\mathrm{N}-\triangle \mathrm{C} 70-\mathrm{REV}$ & $5^{\prime}$-ATggatccGAGAACAAGGTTACCAATGAGGC-3' \\
\hline \multirow[t]{2}{*}{ LDV-N- $\Delta \mathrm{C} 82$} & $\mathrm{~N}-\Delta \mathrm{C} 82-\mathrm{FWD}$ & 5'-ATggatccATGTCTCAAAATAAGAAGAA-3' \\
\hline & $\mathrm{N}-\triangle \mathrm{C} 82-\mathrm{REV}$ & 5'-ATggatccGATTTATTCTGTCCGGCATTGCG-3' \\
\hline
\end{tabular}



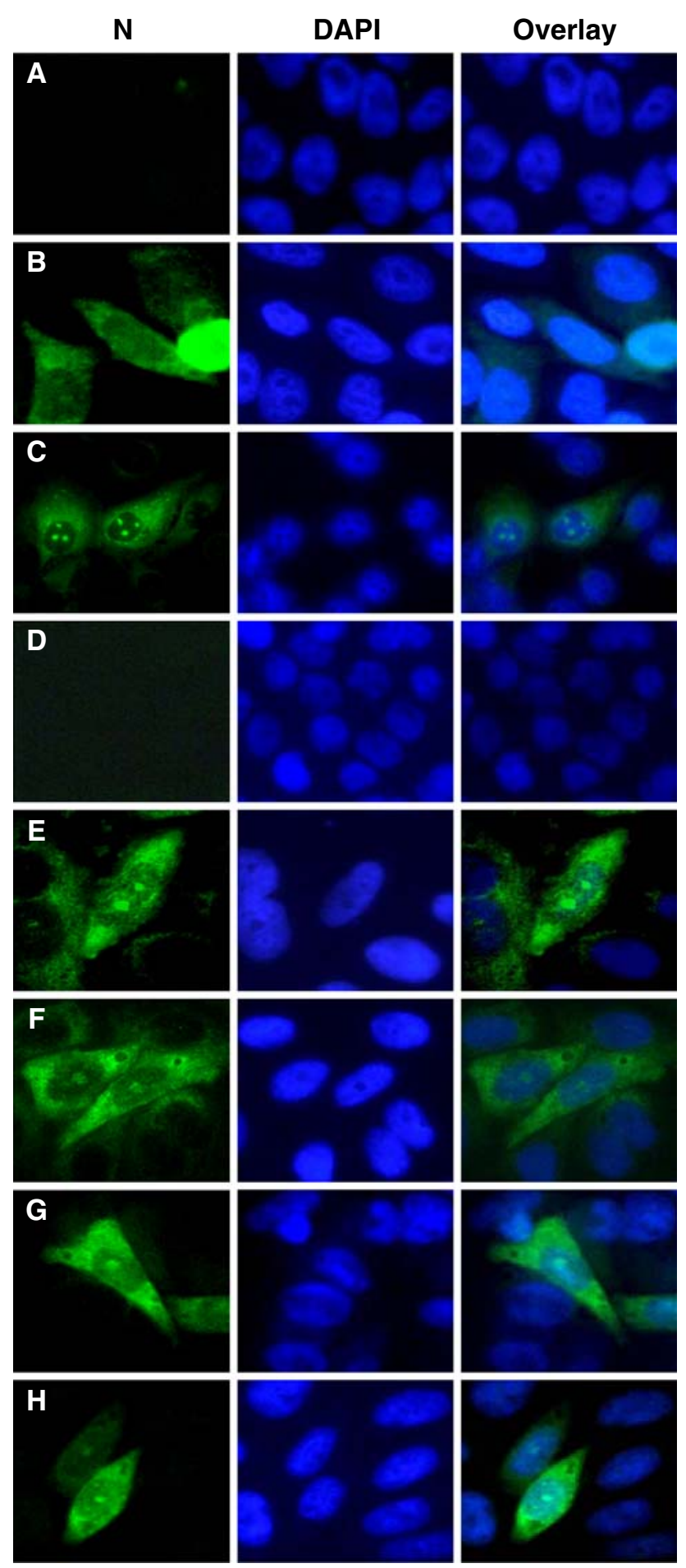

conditions: preincubation for $5 \mathrm{~min}$ at $37^{\circ} \mathrm{C}$, denaturation for $30 \mathrm{~s}$ at $95^{\circ} \mathrm{C}$, annealing for $1 \mathrm{~min}$ at $56^{\circ} \mathrm{C}$, and extension for $1 \mathrm{~min}$ at $72^{\circ} \mathrm{C}$ per cycle for 35 cycles, and final extension for $10 \mathrm{~min}$ at $72^{\circ} \mathrm{C}$ in a GeneAmp 2400 thermocycler (Perkin Elmer). PCR products were digested with BamH1 and subcloned into pEGFP-N1. Each construct was verified by restriction digestion and nucleotide sequencing of the junction between $\mathrm{N}$ and EGFP. Cloning and DNA
4 Fig. 1 Subcellular localization of LDV-N protein. HeLa cells grown on coverslips were transfected with EGFP-LDV-N fusion protein genes using Lipofectin. At $24 \mathrm{~h}$ post-transfection, cells were fixed with methanol and stained with DAPI for nuclear staining. PRRSVinfected MARC-145 cells were stained with SDOW-17 MAb, followed by staining with goat anti-mouse Ab conjugated with Alexa Fluor 488 and finally with DAPI for nuclear staining. Cells on the coverslips were visualized by fluorescence microscopy (model AX70, Olympus). a HeLa cells without transfection; b HeLa cells with the pEGFP-N1 empty vector; c PRRSV-infected MARC-145 cells stained with the N-specific MAb SDOW-17; d PRRSV-infected MARC-145 cells stained with bovine coronavirus spike-protein-specific MAb; e HeLa cells with PRRSV-N gene stained with SDOW-17; f HeLa cells with PRRSV-N-GFP; $g$ HeLa cells with LDV-N-EGFP; h HeLa cells with EGFP-LDV-N

manipulations were conducted according to standard protocols [30]. For mutagenesis, PCR-based site-directed mutagenesis was performed by overlapping extension using mismatch primers as described (Table 1) [39]. PCR was carried out using $15 \mathrm{ng}$ of pLDV-N-EGFP plasmid DNA, $300 \mathrm{ng}$ of each forward and reverse primer, $1 \mathrm{mM}$ dNTPs, $1 \times$ buffer $\left[10 \mathrm{mM} \mathrm{KCl}, 10 \mathrm{mM}\left(\mathrm{NH}_{4}\right)_{2} \mathrm{SO}_{4}\right.$, $20 \mathrm{mM}$ Tris- $\mathrm{HCl}(\mathrm{pH} 8.8), 2 \mathrm{mM} \mathrm{MgSO}_{4}, 0.1 \%$ Triton $\mathrm{X}-100]$, and 2.5 units of $P f u$ DNA polymerase (Stratagene) for 16 cycles as follows: denaturation at $94^{\circ} \mathrm{C}$ for $30 \mathrm{~s}$, primer annealing at $56^{\circ} \mathrm{C}$ for $1 \mathrm{~min}$, and primer extension at $68^{\circ} \mathrm{C}$ for $8 \mathrm{~min}$. The PCR products were digested with $D p n I$ and used to transform E. coli XL1-Blue. Transformants were randomly selected for plasmid DNA preparation using a QIAprep spin miniprep kit (QIAGEN, Santa Clarita, CA), and mutagenized sequences were verified by nucleotide sequencing in both directions.

\section{Fluorescent microscopy}

Expression of N-GFP fusion proteins was determined in HeLa cells by transfection using Lipofectin (Invitrogen) according to the manufacturer's instruction. Cells were grown on microscope coverslips and transfected with GFP fusion constructs of LDV-N. PRRSV N gene and PRRSV N-GFP fusion constructs were included as positive controls [37]. At $24 \mathrm{~h}$ post-transfection, cells were fixed with methanol and blocked with $1 \%$ bovine serum albumin (BSA) in phosphate-buffered saline (PBS) for $30 \mathrm{~min}$, and fluorescence was observed using a fluorescence microscope (model AX70, Olympus). For PRRSV-infected cells, N protein was stained with MAb SDOW-17 [19] at a dilution of $1: 400$ in $1 \%$ BSA-PBS, followed by goat anti-mouse antibody conjugated with AlexaFluor 488 (Molecular Probes) at a dilution of 1:100. After five washes with PBS, cells were stained with DAPI (4',6-diamidino-2-phenylindole dihydrochloride, Sigma) for $5 \mathrm{~min}$, washed again, and mounted on a slide using $40 \mu \mathrm{l}$ of the mounting buffer (60\% glycerol, $0.1 \%$ sodium azide in PBS), and fluorescence was examined by microscopy. 
GST-fusion protein expression and coupling with Sepharose beads

Mouse importin- $\alpha$ and importin- $\beta$ genes were cloned into pGEX-3X (Amersham, Piscataway, NJ) and expressed as glutathione- $S$-transferase (GST)-importin- $\alpha$ and GST-importin- $\beta$ fusion proteins. One ml of Luria-Bertani medium containing $100 \mu \mathrm{g} / \mathrm{ml}$ of ampicillin was inoculated with $1 / 100$ of an overnight culture. When the optical density of the culture reached 0.6 at $600 \mathrm{~nm}$, IPTG (isopropyl- $\beta$-Dthiogalactopyranoside) was added to a final concentration of $1 \mathrm{mM}$, and the culture was incubated further for $3 \mathrm{~h}$. Bacterial cells were collected by centrifugation at $6,000 \mathrm{rpm}$ for $10 \mathrm{~min} 4^{\circ} \mathrm{C}$ (Avanti J30I, Beckman) and resuspended in $10 \mathrm{ml}$ of PBS. The bacterial suspension was sonicated on ice three times (model W-385; Ultrasonics Inc.), each time for $30 \mathrm{~s}$ with 2-s intervals. The suspension was incubated with $1 \%$ Triton $\mathrm{X}-100$ for $30 \mathrm{~min}$ at $4{ }^{\circ} \mathrm{C}$ with occasional agitation and centrifuged at 10,000 rpm for $10 \mathrm{~min}$ at $4^{\circ} \mathrm{C}$ to remove the insoluble fractions and cell debris. The supernatant, which contained expressed GSTfusion proteins was incubated with $100 \mu$ l of glutathioneSepharose 4B beads (Amersham) in a 50\% slurry overnight at $4{ }^{\circ} \mathrm{C}$ with constant agitation. GST-fusion proteins bound to beads were centrifuged and washed five times in PBS containing $1 \%$ Triton X-100. The collected beads were then resuspended in a final volume of $250 \mu$ of incubation buffer [20 mM Tris- $\mathrm{HCl}(\mathrm{pH} 7.5), 100 \mathrm{mM} \mathrm{KCl,} 2 \mathrm{mM}$ $\mathrm{CaCl}_{2}, 2 \mathrm{mM} \mathrm{MgCl}_{2}, 5 \mathrm{mM}$ dithiothreitol, $0.5 \% \mathrm{NP}-40$, $1 \mathrm{mM}$ PMSF, 5\% glycerol]. This resulted in a $20 \%$ slurry of beads to use for GST pull-down assay. For production of radiolabelled $\mathrm{N}$ protein, the $\mathrm{LDV}-\mathrm{N}$ gene was cloned into pCITE (Novogen) and translated using the $\mathrm{TNT}^{\circledR}$ Quick Coupled in vitro Transcription/Translation system (Promega, Madison, WI) in the presence of $\left[{ }^{35} \mathrm{~S}\right]$ methionine (EasyTag EXPRESS protein-labeling mix of $\left[{ }^{35} \mathrm{~S}\right]$ methionine and $\left[{ }^{35}\right.$ S $]$ cysteine; specific activity $407 \mathrm{MBq} / \mathrm{ml}$, Perkin-Elmer) according to the manufacturer's instructions. Based on the quantity as measured by SDS-PAGE, approximately equal amounts of Sepharose-coupled GST
Fig. 2 Identification of an NLS motif in the LDV-N protein and its functional mapping. a A predicted 'pat-4'-type nuclear localization signal in the LDV-N protein identified by the PSORT II program. The PRRSV N protein sequence is aligned for comparison with LDV-N. Dashes indicate deletions. Bold letters with underlining indicate 'pat-4'(for LDV) and 'pat-7'- (for PRRSV) type NLSs sequences with their amino acids positions. b Schematic presentation of LDV-N deletion mutants fused with EGFP. Darkened areas represent predicted NLS at amino acid positions $38-41$
(A)

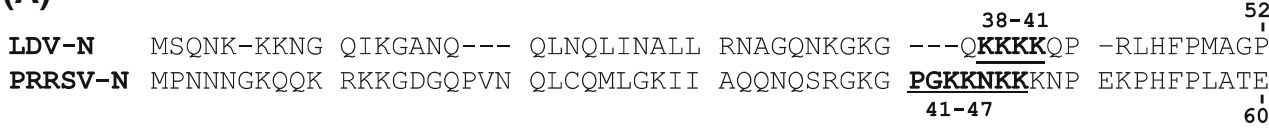

SDIRHVMTPN EVQMCRSSLL TLFNQGGGQC TLVDSGGINY TVSFMLPTHA TVRLINASAN SSA-115 DDVRHHFTPS ERQLCLSSIQ TAFNQGAGTC TLSDSGRISY TVEFSLPTHH TVRLIRVTAS PSA-123

(B)

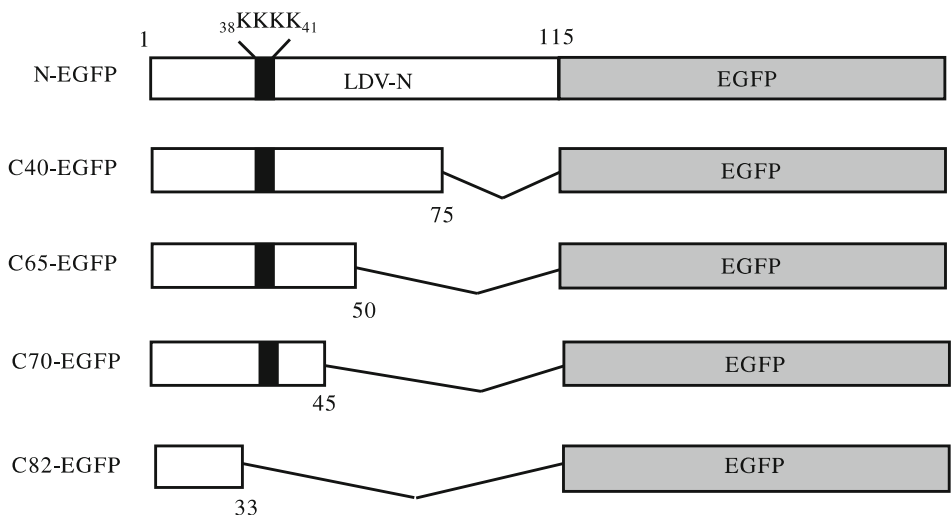

Fig. 3 Subcellular localization of LDV-N mutant proteins. a Wild type LDV-N-EGFP; b deletion constructs LDV-NC40-EGFP; c LDV-N-C65EGFP; d LDV-N-C70-EGFP; e LDV-N-C82-EGFP. Upper images represent GFP expression of the LDV N constructs, and lower images represent the overlay of GFP and DAPI staining of the same area

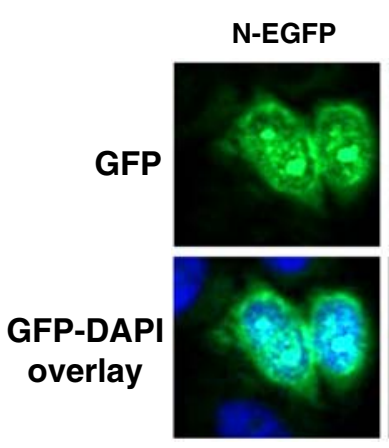

A

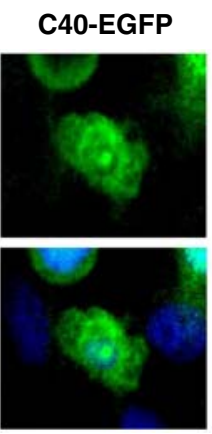

B

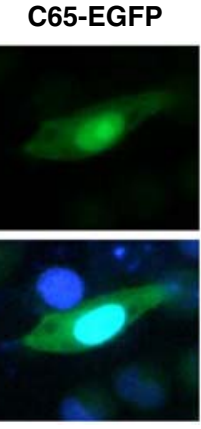

C

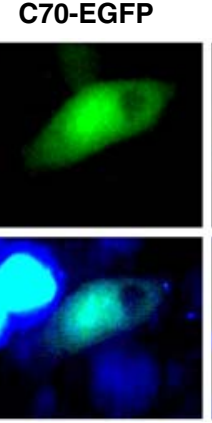

D

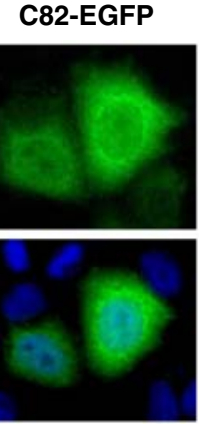

E 
fusion proteins and LDV-N were incubated overnight at $4^{\circ} \mathrm{C}$ with constant agitation. The Sepharose beads were washed five times with PBS, boiled for $5 \mathrm{~min}$ in SDS sample buffer [10 mM Tris-HCl (pH 6.8), 25\% glycerol, $10 \%$ SDS, $10 \% \beta$-mercaptoethanol, and $0.12 \%$ (wt/vol) bromophenol blue], and analyzed by $12 \%$ SDS-PAGE. Gels were dried and exposed for image analysis using a Phosphorimager (Molecular Dynamics).

\section{Results}

Subcellular localization of EGFP-tagged LDV-N

The LDV nucleocapsid protein was expressed as an EGFP$\mathrm{N}$ fusion protein in HeLa cells and examined for subcellular distribution. Cells were counterstained with DAPI for nuclear staining. EGFP alone was distributed throughout transfected cells (Fig. 1, panel b). For the purpose of comparison, localization of the PRRSV N protein in virusinfected MARC-145 cells is shown (Fig. 1, panel c). Detection of PRRSV $\mathrm{N}$ by $\mathrm{N}$-specific MAb SDOW17 showed the accumulation of $\mathrm{N}$ in the nucleus and nucleolus in addition to its normal cytoplasmic distribution. In PRRSV N- and PRRSV N-GFP-transfected cells, N accumulated in the nucleus (Fig. 1, panels e, f), and similarly, both LDV-N-EGFP and LDV-EGFP-N fusion proteins showed an accumulation of fluorescence in the nucleus (Fig. 1, panels g, h), with a distribution pattern similar to that of PRRSV N, indicating that LDV-N localized both in the cytoplasm and the nucleolus.

Identification and mapping of the NLS in the LDV-N protein

Sequence analysis of the LDV-N protein identified the presence of a single basic region of KKK which resembled a 'pat-4' type NLS located between amino acid positions 38-41 (Fig. 2a). The location of this lysine-rich region corresponded to the 'pat-7' motif of the PRRSV N protein. To determine the functional significance of the 'pat-4' motif of LDV-N, a series of deletion mutants were made by progressively deleting from the C-terminus of $\mathrm{N}$ (Fig. 2b). Cells were then transfected with the mutant constructs, and their fluorescence was examined. LDV-N-C40-EGFP, LDV-N-C65-EGFP, and LDV-N-C70-EGFP showed fluorescence in the nucleus and nucleolus (Fig. 3, panels b, c, d). In contrast, LDV-N-C82-EGFP, in which the putative motif was deleted, yielded cytoplasmic fluorescence but not nuclear fluorescence (panels e). These results indicate that the predicted 'pat-4' motif was indeed a functional NLS that translocates LDV-N to the nucleus and nucleolus of cells.
To further confirm the function of the predicted NLS and to examine amino acids important for this function, individual residues of ' $38-\mathrm{KKKK}-41$ ' were substituted with glycine $(\mathrm{G})$ at single or multiple sites (Table 2), and the individual mutants were expressed in HeLa cells (Fig. 4). The data showed that two ' $K$ 's at positions 38 and 40 are important for nucleolar localization of LDV N, and the residues at positions 38,40 , and 41 play a crucial role for this function (Table 2; Fig. 4). The mutant in which all four ' $K$ 's were substituted with ' $G$ 's became exclusively cytoplasmic and did not localize to the nucleus or the nucleolus (Fig. 5a). This confirms that the predicted 'pat-4' motif was indeed the functional NLS for nuclear localization of the LDV-N protein. Since LDV is a murine virus and HeLa cells were used for this study, the NLS function of LDV-N was further confirmed in mouse cells using the same constructs (Fig. 5b). NIH-3T3 cells were transfected with either wild-type or NLS-null mutant LDV-N and their fluorescence patterns were examined. As expected, the PRRSV N protein was found in the nucleus and nucleolus in the murine cells. For LDV-N, the nucleolar localization was evident for the wild-type N protein, whereas the NLSnull mutant protein was cytoplasmic without distinct nuclear staining, indicating that the LDV-N nuclear localization is not cell-type-dependent but is rather a natural property of the $\mathrm{N}$ protein.

Table 2 Site-directed mutagenesis of the LDV-N NLS motif and subcellular localization of NLS mutants

\begin{tabular}{lllll}
\hline Construct & $\begin{array}{l}\text { Sequence } \\
\text { of NLS }\end{array}$ & \multicolumn{3}{l}{ Localization $^{\mathrm{b}}$} \\
\cline { 2 - 5 } & & $\mathrm{Cy}$ & $\mathrm{Nu}$ & No \\
\hline LDV-N & 38 -KKKK-41 & ++++ & ++ & ++++ \\
LDV-N-K38G & 38 -GKKK-41 & ++++ & ++++ & +++ \\
LDV-N-K39G & $38-K G K K-41$ & ++++ & +++ & + \\
LDV-N-K40G & $38-K K G K-41$ & ++++ & ++ & + \\
LDV-N-K41G & $38-K K K G-41$ & ++++ & ++++ & +++ \\
LDV-N-K38,39G & $38-G G K K-41$ & ++++ & ++++ & + \\
LDV-N-K38,40G & $38-G K G K-41$ & ++++ & ++ & + \\
LDV-N-K38,41 K & $38-G K K G-41$ & ++++ & +++ & + \\
LDV-N-K39,40G & $38-K G G K-41$ & ++++ & +++ & ++ \\
LDV-N-K39,41G & $38-K G K G-41$ & ++++ & +++ & + \\
LDV-N-K40,41G & $38-K K G G-41$ & ++++ & +++ & \pm \\
LDV-N-K39,40,41G & $38-K G G G-41$ & ++++ & +++ & \pm \\
LDV-N-K38,39,40G & $38-G G G K-41$ & ++++ & +++ & \pm \\
LDV-N-K38,39,40,41G & $38-G G G G-41$ & ++++ & - & - \\
\hline
\end{tabular}

${ }^{a}$ Individual lysines $(\mathrm{K})$ in the NLS were substituted with glycines (G)

${ }^{b}$ For scoring of the fluorescence signal for each mutant construct, 100 transfected cells were counted and presented as + or - . Each one ' + ' represents fluorescence of 25 transfected cells either in the cytoplasm $(\mathrm{Cy})$, nucleus $(\mathrm{Nu})$, or nucleolus $(\mathrm{No})$ 
Fig. 4 Subcellular localization of NLS mutants. a-d single substitutions of LDV-N (LDV-N-K38G, LDV-N-K39G, LDV-N-K40G, and LDV-N$\mathrm{K} 41 \mathrm{G}$, respectively) $\mathbf{e}-\mathbf{j}$ are double mutations in NLS (LDVN-K38,39G, LDV-N-K38,40G, LDV-N-K38,41K, LDV-NK39,40G, LDV-N-K39,41G, LDV-N-K40,41G, respectively). $\mathbf{k}, \mathbf{I}$ are triple mutations in NLS (LDV-N-K39,40,41G and LDV-N-K38,39,40G). a GFP staining; $\mathbf{b}$ the same cells in a overlaid with DAPI staining
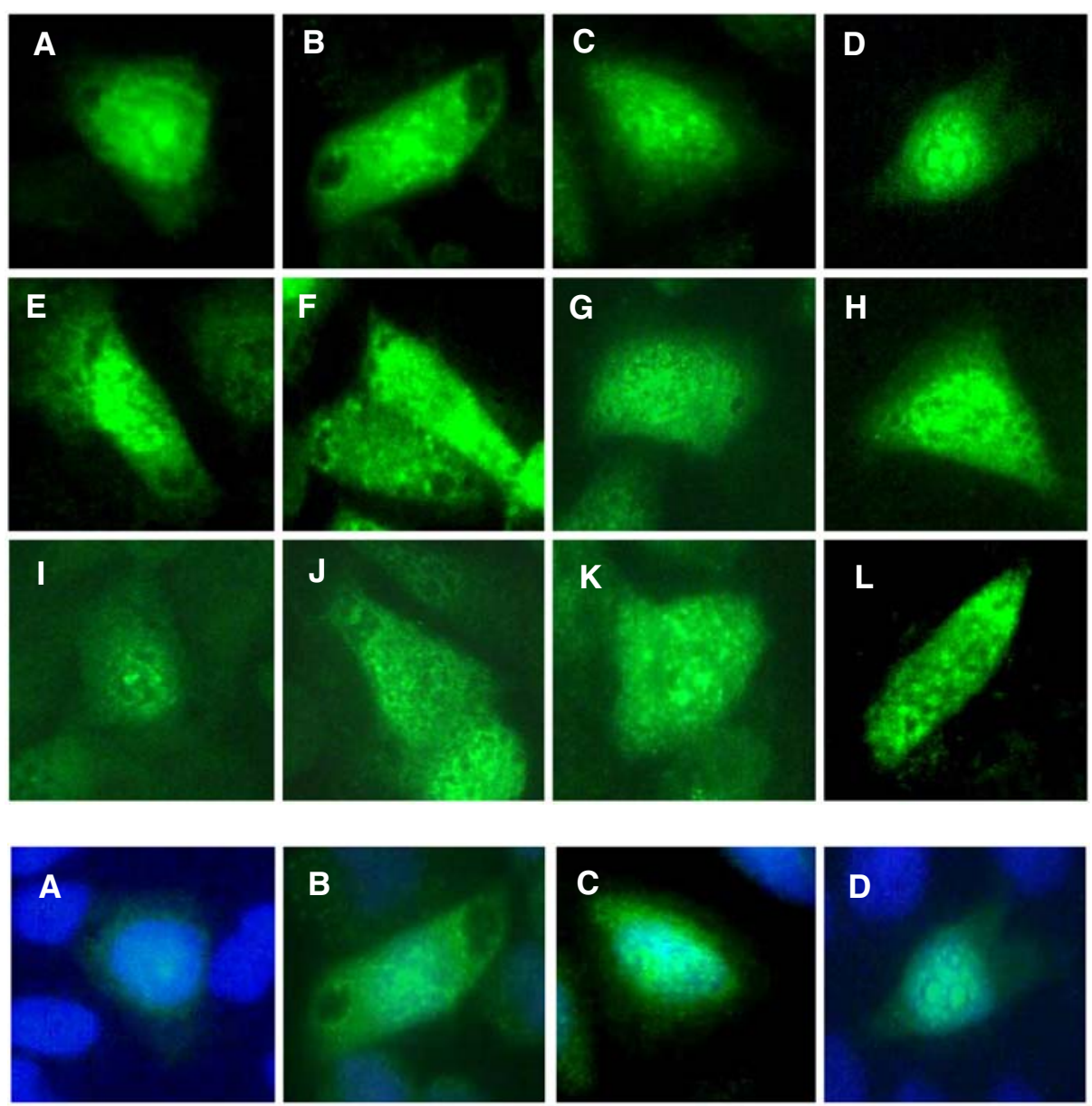

(B)
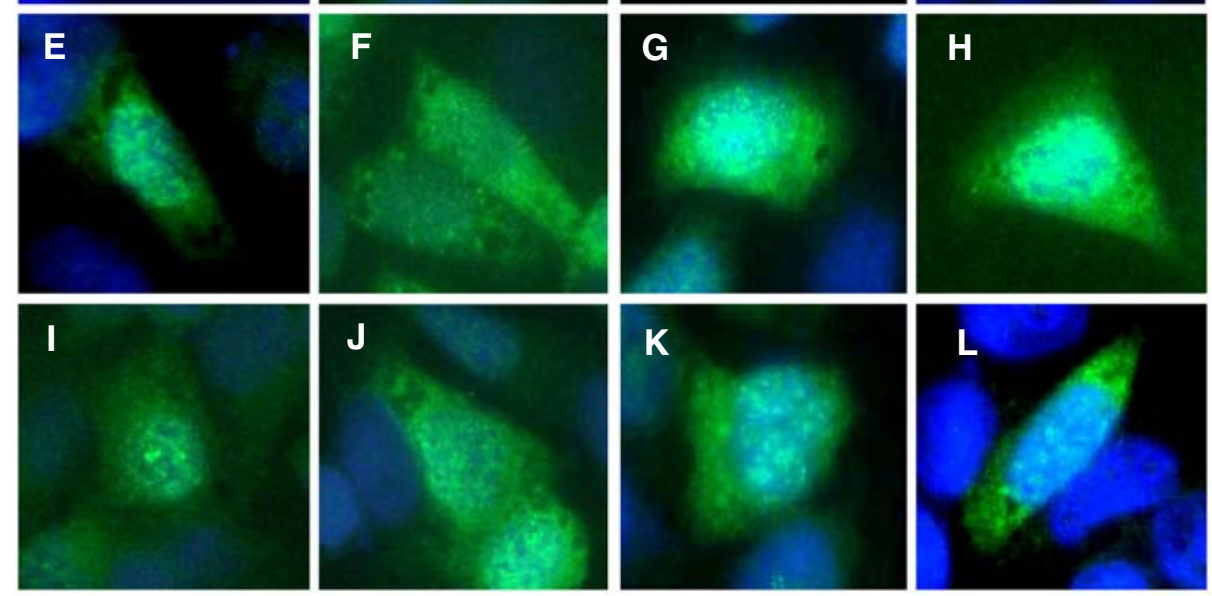

LDV-N interaction with importin proteins

To determine the basis for LDV-N nuclear localization, interactions between $\mathrm{N}$ and importin proteins were determined by GST pull-down assay. Importin- $\alpha$ and importin- $\beta$ were individually expressed in $E$. coli as a GST-fusion proteins and coupled to glutathione-Sepharose beads. The radiolabelled LDV-N protein was then synthesized in vitro by transcription and translation, and importin-coupled GST beads were incubated with the radiolabelled $\mathrm{N}$ protein.
Unbound proteins were washed off and the bound proteins were resolved by SDS-PAGE and autoradiography. As with the PRRSV N protein, which was previously shown to interact with both importin- $\alpha$ and $-\beta$ proteins [27]; (Fig. 6, lanes 7 and 9), both importin- $\alpha$ and importin- $\beta$ specifically bound LDV-N (lanes 8 and 10), while GST alone did not bind to PRRSV-N or LDV-N (lanes 5 and 6). This study demonstrates the specific interaction of LDV-N with both importin proteins and suggests that LDV-N nuclear localization may be importin-mediated. 
Fig. 5 Subcellular localization of the NLS-null LDV-N-EGFP mutants in HeLa cells a and NIH-3T3 cells b. The NLS (38-KKKK-41) of LDV-N was mutated to 38 -GGGG-41 to knock out the NLS function. HeLa cells or NIH-3T3 cells were transfected with the NLSnull LDV-N gene, followed by staining with DAPI for

fluorescent microscopy. LDV$\mathrm{N}$-wt, wild-type LDV-N-EGFP; LDV-N-null, NLS-null mutant LDV-N-EGFP; PRRSV-N, porcine reproductive respiratory syndrome virus wild-type $\mathrm{N}$ protein
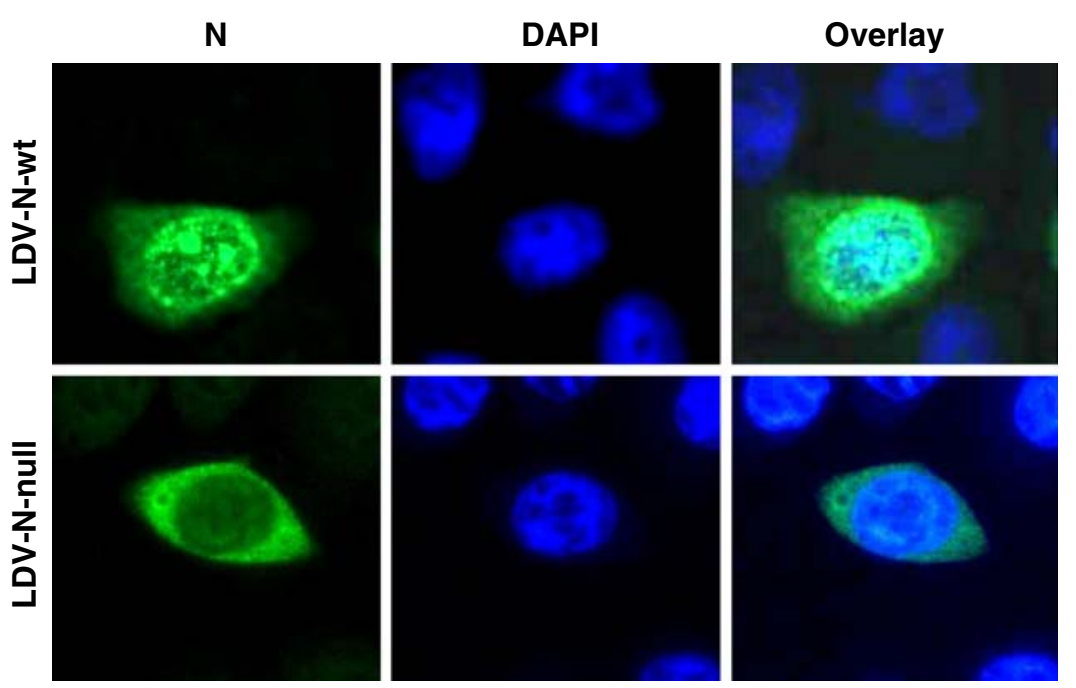

(A)
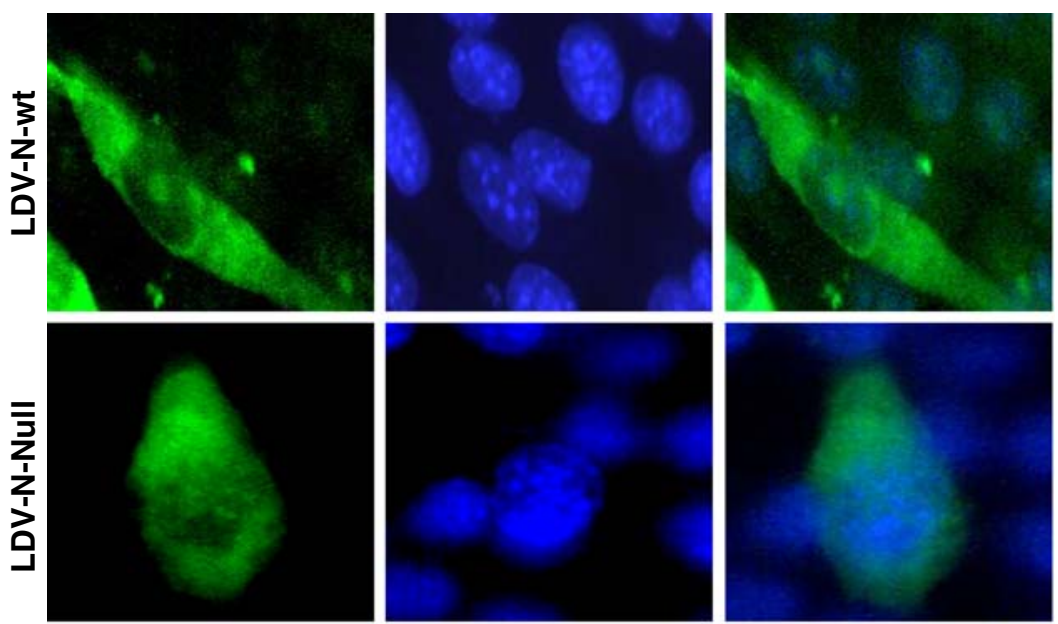

(B)

NIH-3T3
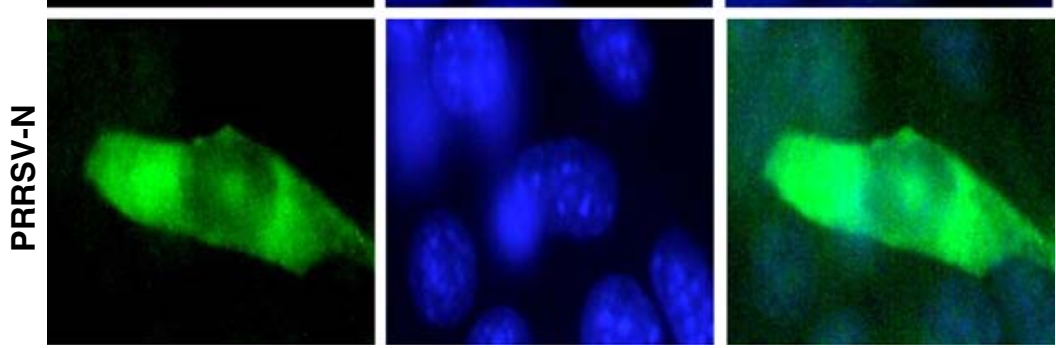

HeLa

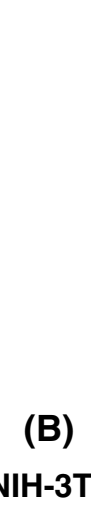

\section{Discussion}

Nuclear localization of the capsid protein has been studied for several RNA viruses that restrict their replication to the cytoplasm, and capsid proteins of Semliki Forest virus, dengue virus, and hepatitis $\mathrm{C}$ virus have been shown to localize in the nucleus and nucleolus [7, 36, 41]. Nidoviruses also replicate exclusively in the cytoplasm of infected cells [1], but the $\mathrm{N}$ protein has been shown to localize in the nucleus and nucleolus for PRRSV, EAV, IBV, MHV and TGEV [6, 10, 25, 35, 40, 45]. The N protein of PRRSV contains two putative NLS motifs, 'pat 4' and 'pat 7', and the "pat 7" located at positions $41-47$ has been shown to be the active and primary NLS for N [27]. In the present study, we showed that the LDV-N protein localized to the nucleus and nucleolus in cells transfected with the N-EGFP gene, and using mutant constructs, we showed that the nuclear localization of $\mathrm{N}$ was dependent on a 'pat-4' motif located at positions 38-41 (Figs. 2a, 3). The location of the 'pat-4' motif in LDV-N is similar to the region where the functional 'pat 7' motif is located in PRRSV N. We further identified two lysine residues at positions 38 and 40 in LDV-N that form core residues for nuclear transport of $\mathrm{N}$. For PRRSV N, amino acids at positions 43 and 44 are critical residues for nuclear localization [14, 21, 27]. For a protein to localize in the nucleus, the cellular chaperone 


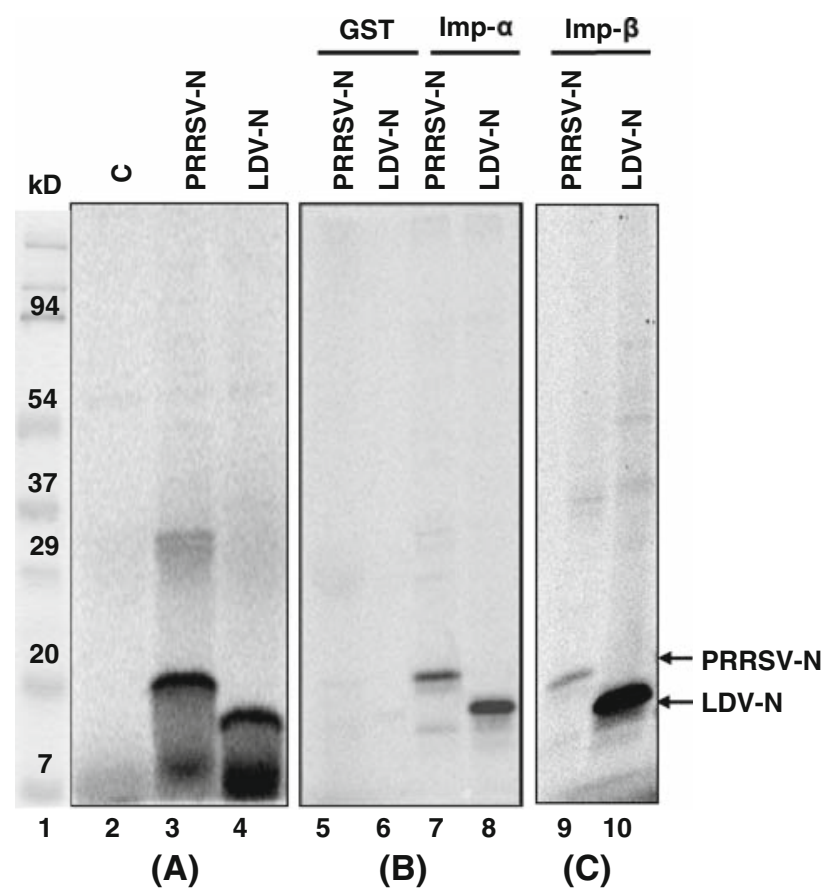

Fig. 6 Interactions of LDV-N with importin proteins shown by GSTpull down assays. Mouse importin- $\alpha$ - and importin- $\beta$-glutathione$S$-transferase (GST) fusion proteins were expressed in E-coli and coupled to glutathione-Sepharose 4B beads. Proteins bound to beads were incubated overnight at $4^{\circ} \mathrm{C}$ with in vitro-translated radiolabelled $\mathrm{N}$ protein. After washing, bound proteins were visualized by $12 \%$ SDS-PAGE and autoradiography. a In vitro translation of the vector control (lane 2), PRRSV-N (lane 3), and LDV-N (lane 4). b, c GST pull-down assays for LDV-N by importin- $\alpha$ (lane 8 ) and importin- $\beta$ (lane 10), respectively

importin- $\alpha$ recognizes the NLS on the cargo protein, and subsequently, importin- $\beta$ binds to the importin- $\alpha /$ cargo protein complex, transporting the complex in the presence of Ran-GDP to NPC on the nuclear membrane $[8,17]$. We found that LDV-N binds to importin- $\alpha$ (Fig. 6, lane 8), which is consistent with the utilization of the classical pathway for nuclear transport. It is interesting to note that LDV-N also binds to importin- $\beta$ (Fig. 6, lane 10). PRRSV $\mathrm{N}$ also binds to both importin- $\alpha$ and importin- $\beta$ [27], and several other viral proteins have been reported to interact with both importin- $\alpha$ and $-\beta$. The polyomavirus capsid protein requires interaction with both importin- $\alpha$ and $-\beta$ to enter the nucleus [23], and SV40 VP3 also interacts with both importin proteins for nuclear translocation [17]. The HIV Rev protein binds both importin- $\alpha$ and $-\beta$, but its binding to importin- $\alpha$ is NLS-independent, while importin$\beta$ binding is NLS-dependent [9]. For PRRSV, two nucleolar proteins, nucleolin and B23, have been shown to bind to $\mathrm{N}$ (unpublished data), and thus a possible mechanism for LDV-N nuclear transport is the use of an importin-dependent pathway with a 'piggy-backing' mechanism, in which $\mathrm{N}$ binds to a nuclear-targeted cellular protein in addition to importin proteins.
Since $\mathrm{N}$ proteins of PRRSV, EAV, and LDV all localize to the nucleus and nucleolus, the nuclear role of $\mathrm{N}$ during infection is of major interest. The core protein of hepatitis $\mathrm{C}$ virus is believed to modify cellular function by preventing translocation of host cell proteins to the nucleus $[12,34]$, and the $\mathrm{N}$ protein of TGEV has been suggested to play a role in the disruption of cell division [40]. For PRRSV N, disruption of NLS does not affect virus replication in cell culture, but in pigs, NLS-null viruses are attenuated in their virulence [14, 21]. The NLS motif of PRRSV $\mathrm{N}$ was associated with strong selective pressure for reacquisition of the nuclear function in vivo, suggesting the involvement of $\mathrm{N}$ nuclear localization in viral pathogenesis. $\mathrm{N}$ proteins of several member viruses in the order Nidovirales colocalize and interact with fibrillarin and nucleolin in the nucleolus, supporting the hypothesis that $\mathrm{N}$ modulates host-cell ribosomal biogenesis and cell cycle progression [5, 11]. In summary, we show that LDV-N contains a functional 'pat-4'-type NLS at positions 38-41 and localizes in the nucleolus of cell via the importin-mediated pathway. The nuclear localization of the capsid protein may be a common feature of members of the family Arteriviridae and may play a common role for replication and pathogenesis of this group of viruses.

Acknowledgments This study was supported by USDA National Research Initiative Competitive Grants Program (2008-35204-04634) to DY. Hakimeh Mohammadi is a scholarship recipient of the Iranian Ministry of Health and Medical Education.

\section{References}

1. Brayton PR, Ganges RG, Stohlman SA (1981) Host cell nuclear function and murine hepatitis virus replication. J Gen Virol $56: 457-460$

2. Brinton-Darnell M, Plagemann PGW (1975) Structure and chemical-physical characteristics of lactate dehydrogenaseelevating virus and its RNA. J Virol 16:420-433

3. Brinton-Darnell M, Collins K, Plagemann PGW (1975) Lactate dehydrogenase-elevating virus replication, maturation, and viral RNA synthesis in primary mouse macrophage cultures. Virology 65:187-195

4. Cafruny WA, Plagemann PGW (1982) Immune response to lactate dehydrogenase-elevating virus: serologically specific rabbit neutralizing antibody to the virus. Infect Immun 37:1007-1012

5. Chen H, Wurm T, Britton P, Brooks G, Hiscox JA (2002) Interaction of the coronavirus nucleoprotein with nucleolar antigens and the host cell. J Virol 76:5233-5250

6. Evans MR, Simpson RW (1980) The coronavirus avian infectious bronchitis virus requires the cell nucleus and host transcriptional factors. Virology 105:582-591

7. Favre D, Studer E, Michel MR (1994) Two nucleolar targeting signals present in the N-terminal part of Semliki Forest virus capsid protein. Arch Virol 137:149-155

8. Gorlich D, Kutay U (1999) Transport between the cell nucleus and the cytoplasm. Ann Rev Cell Dev Biol 15:607-660 
9. Henderson BR, Percipalle P (1997) Interactions between HIV Rev and nuclear import and export factors: the Rev nuclear localization signal mediates specific binding to human importinB. J Mol Biol 274:693-707

10. Hiscox JA, Wurm T, Wilson L, Britton P, Cavanagh D, Brooks G (2001) The coronavirus infectious bronchitis virus nucleoprotein localizes to the nucleolus. J Virol 75:506-512

11. Hiscox JA (2007) RNA viruses: hijacking the dynamic nucleolus. Nat Rev Microbiol 5:119-127

12. Isoyama T, Kuge S, Nomoto A (2002) The core protein of hepatitis $\mathrm{C}$ virus is imported into the nucleus by transport receptor Kap123p but inhibits Kap121p-dependent nuclear import of yeast AP1-like transcription factor in yeast cells. J Biol Chem 277: 39634-39641

13. Kim HS, Kwang J, Yoon LJ, Joo HS, Frey ML (1993) Enhanced replication of porcine reproductive and respiratory syndrome (PRRS) virus in a homogeneous subpopulation of MA-104 cell line. Arch Virol 133:477-483

14. Lee C, Hodgins D, Calvert JG, Welch SK, Jolie R, Yoo D (2006) Mutations within the nuclear localization signal of the porcine reproductive and respiratory syndrome virus nucleocapsid protein attenuate virus replication. Virology 346:238-250

15. Martinez D, Brinton MA, Tachovsky TG, Phelps AH (1980) Identification of lactate dehydrogenase elevating virus as the etiological agent of genetically restricted, age-dependent polioencephalomyelitis of mice. Infect Immun 27:979-987

16. Nakai K, Kanehisa M (1992) A knowledge base for predicting protein localization sites in eukaryotic cells. Genomics 14: 897-911

17. Nakanishi A, Shum D, Morioka H, Otsuka E, Kasamatsu H (2002) Interaction of the Vp3 nuclear localization signal with the importin $\alpha 2 / \beta$ heterodimer directs nuclear entry of infecting Simian virus 40. J Virol 76:9368-9377

18. Nawrocki JF, Pease LR, Murphy WH (1980) Etiologic role of lactic dehydrogenase virus infection in an age dependent neuroparalytic disease in C58 mice. Virology 103:259-264

19. Nelson EA, Christopher-Hennings J, Drew T, Wensvoort G, Collins JE, Benfield DA (1993) Differentiation of US and European isolates of porcine reproductive and respiratory syndrome virus by monoclonal antibodies. J Clin Microbiol 31: 3184-3189

20. Onyekaba CO, Harty JT, Plagemann PGW (1989) Extensive cytocidal replication of lactate dehydrogenase-elevating virus in cultured peritoneal macrophages from 1-2 week-old mice. Virus Res 14:327-338

21. Pei Y, Hodgins DC, Lee C, Calvert JG, Welch SK, Jolie R, Keith M, Yoo D (2008) Functional mapping of the porcine reproductive and respiratory syndrome virus capsid protein nuclear localization signal and its pathogenic association. Virus Res 135:107-114

22. Plagemann PGW, Rowland RR, Even C, Faaberg KS (1995) Lactate dehydrogenase-elevating virus. An ideal persistent virus? Semin Immunopathol 17:167-186

23. Qu Q, Sawa H, Suzuki T, Semba S, Henmi C, Okada Y, Tsuda M, Tanaka S, Atwood WJ, Nagashima K (2004) Nuclear entry mechanism of the human polyomavirus JC virus-like particle, role of importins and the nuclear pore complex. J Biol Chem 279:27735-27742

24. Riley V, Lilly F, Huerto E, Bardell D (1960) Transmissible agent associated with 26 types of experimental mouse neoplasms. Science 132:545-547

25. Rowland RRR, Kervin R, Kuckleburg C, Sperlich A, Benfield DA (1999) The localization of porcine reproductive and respiratory syndrome virus nucleocapsid protein to the nucleolus of infected cells and identification of a potential nucleolar localization signal sequence. Virus Res 64:1-12
26. Rowland RRR, Yoo D (2003) Nucleolar-cytoplasmic shuttling of PRRSV nucleocapsid protein: a simple case of molecular mimicry or the complex regulation by nuclear import, nucleolar localization and nuclear export signal sequences. Virus Res 95: 23-33

27. Rowland RRR, Schneider P, Fang Y, Wootton S, Yoo D, Benfield DA (2003) Peptide domains involved in the localization of the porcine reproductive and respiratory syndrome virus nucleocapsid protein to the nucleolus. Virology 316:135-145

28. Rowland RRR, Chauhan V, Fang Y, Pekosz A, Kerrigan M, Burton MD (2005) Intracellular localization of the severe acute respiratory syndrome coronavirus nucleocapsid protein: absence of nucleolar accumulation during infection and after expression as a recombinant protein in Vero cells. J Virol 79:11507-11512

29. Rowson KEK, Mahy WJ (1985) Lactate dehydrogenase-elevating virus. J Gen Virol 66:2297-2312

30. Sambrook J, Russell DW (2001) Molecular cloning: a laboratory manual, 3rd edn. Cold Spring Harbor Laboratory, Cold Spring Harbor

31. Snijder EJ, Meulenberg JM (1998) The molecular biology of arteriviruses. J Gen Virol 79:961-979

32. Snijder EJ, Spaan WJM (2007) Arteriviruses. In: Knipe DM, Howley PM, Griffin DE, Lamb RA, Martin MA, Roizman B, Straus SE (eds) Field's virology, 5th edn. Lippincott Williams and Wilkins, Philadelphia, pp 1337-1355

33. Stueckemann JA, Ritzi DM, Holth M, Smith MS, Swart WJ, Cafruny WA, Plagemann PGW (1982) Replication of lactate dehydrogenase-elevating virus in macrophages. Evidence for cytocidal replication. J Gen Virol 59:245-262

34. Suzuki R, Sakamoto S, Tsutsumi T, Rikimaru A, Tanaka K, Shimoike T, Moriishi K, Iwasaki T, Mizumoto K, Matsuura Y, Miyamura T, Suzuki T (2005) Molecular determinants for subcellular localization of hepatitis $\mathrm{C}$ virus core protein. J Virol 79:1271-1281

35. Tijms MA, van der Meer Y, Snijder EJ (2002) Nuclear localization of non-structural protein 1 and nucleocapsid protein of equine arteritis virus. J Gen Virol 83:795-800

36. Wang SH, Syu WJ, Huang KJ, Lei HY, Yao CW, King CC, Hu ST (2002) Intracellular localization and determination of a nuclear localization signal of the core protein of dengue virus. J Gen Virol 83:3093-3102

37. Wootton SK, Nelson EA, Yoo D (1998) Antigenic structure of the nucleocapsid protein of porcine reproductive and respiratory syndrome virus. Clin Diagn Lab Immunol 5:773-779

38. Wootton SK, Yoo D, Rogan D (2000) Full-length sequence of a Canadian porcine reproductive and respiratory syndrome virus (PRRSV) isolate. Arch Virol 145:2297-2323

39. Wootton SK, Koljesar G, Yang L, Yoon KJ, Yoo D (2001) Antigenic importance of the carboxy-terminal beta-strand of the porcine reproductive and respiratory syndrome virus nucleocapsid protein. Clin Diagn Lab Immunol 8:598-603

40. Wurm T, Chen H, Hodgson T, Britton P, Brooks G, Hiscox JA (2001) Localization to the nucleolus is a common feature of coronavirus nucleoproteins and the protein may disrupt host cell division. J Virol 75:9345-9356

41. Yasui K, Wakita T, Tsukiyama-Kohara K, Funahashi SI, Ichikawa M, Kajita T, Moradpour D, Wands JR, Kohara M (1998) The native form and maturation process of hepatitis C virus core protein. J Virol 72:6048-6055

42. Yoo D, Wootton SK, Li G, Song C, Rowland RR (2003) Colocalization and interaction of the porcine arterivirus nucleocapsid protein with the small nucleolar RNA-associated protein fibrillarin. J Virol 77:12173-12183

43. You JH, Dove BK, Enjuanes L, de Alvarez E, Howell G, Heinen P, Zambon M, Hiscox JA (2005) Subcellular localization of the 
severe acute respiratory syndrome coronavirus nucleocapsid protein. J Gen Virol 86:3303-3310

44. You JH, Reed ML, Hiscox JA (2007) Trafficking motifs in the SARS-coronavirus nucleocapsid protein. Biochem Biophy Res Comm 358:1015-1020
45. You JH, Howell G, Pattnaik AK, Osorio FA, Hiscox JA (2008) A model for the dynamic nuclear/nucleolar/cytoplasmic trafficking of the porcine reproductive and respiratory syndrome virus (PRRSV) nucleocapsid protein based on live cell imaging. Virology 378:34-47 